\title{
The Effect of Price Regulation on Innovation in the Pharmaceutical Industry
}

Jennifer L. Troyer, (E-mail: jtroyer@email.uncc.edu), University of North Carolina at Charlotte Alexander V. Krasnikov, (E-mail: avkrasnikov@yahoo.com), University of North Carolina at Charlotte

\begin{abstract}
The empirical relationship between pharmaceutical industry revenues and pharmaceutical industry innovation is estimated, allowing for an exploration of the impact of the Medicaid rebate program, a form of price regulation. Using the empirical results, the opportunity cost of the Medicaid rebate program is found to be as high as four new drug approvals annually. Given the increased interest in a Medicare drug benefit, regulators should be aware of the hidden cost of price regulation for pharmaceuticals.
\end{abstract}

\section{Introduction}

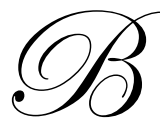

reakthrough medicines and vaccines played a central role in the twentieth century's unprecedented advances in the treatment of many fatal diseases in the United States. Yet, despite their obvious connection to the health of the general public, the development of new drugs is chiefly a private enterprise. In the U.S., the new drug discovery process relies heavily on research and development (R\&D) investment by pharmaceutical companies. These private firms base their decisions to invest on the risks and returns associated with drug development.

The costs of drug discovery and development have increased over time (PhRMA, 2000b), and the risks of failure are quite high. On average, only three out of ten approved drugs recover average R\&D costs (PhRMA 2000b), and in 1998 private investors suffered \$5 billion losses from unsuccessful investments in biotech and pharmaceutical R\&D (Spitzer, 1999). Due in part to increased research and development costs, increases in drug prices have outpaced increases in the general price level in recent years.

As pharmaceutical prices have risen, government interest in controlling the price of pharmaceutical products has grown, particularly for drugs purchased under the auspices of government funded health programs/agencies. Government, at both federal and state levels, is a major purchaser of pharmaceuticals, through the Medicaid program, Department of Veterans Affairs, Department of Defense, and various other programs. Most government programs that cover prescription drugs mandate various forms of price controls, including rebates, discounts, caps on prices and limits on price increases. Recently, some politicians have proposed expanded Medicare drug coverage for elderly Americans coupled with price regulation of drugs, but little is known about the long-run consequences of price regulation on drug discovery and approval.

Economists have long known that price controls may have negative consequences. One important but rarely studied consequence is a change the incentive to invest in R\&D. Since Solow's seminal 1957 article, which showed that ninety percent of the of the doubling of per capita nonfarm output in the United States over the period 1909-1949 was due to technical advance, the importance of technological innovation in the economy has been known. Thus, an examination of consequences of price regulation on the pace of technological progress in the pharmaceutical industry is in order ${ }^{1}$

In this paper, the relationship between U.S. pharmaceutical industry revenues and industry innovation will be considered. Using information about this relationship, the estimates will be used to predict the cumulative effect

Readers with comments or questions are encouraged to contact the authors via email. 
of rebates received by Medicaid from drug manufacturers on pharmaceutical innovation in the U.S. The analysis will begin with a review of the relevant literature, followed by a discussion of the empirical model and data. Finally, the empirical results will be presented, and the implications will be explored.

\section{Literature Review: Pharmaceutical Regulation}

As mentioned above, governmental entities seek to control the price paid for pharmaceutical products in a number of programs. The most noteworthy is the Medicaid rebate program, where rebates totally over $\$ 3.9$ billion were issued in 2000. The program and its relationship to drug prices will be examined below, followed by a discussion of regulation related to the drug discovery process.

\subsection{Price Regulation Through Medicaid Rebates and Pharmaceutical Innovation}

Established in 1990, the Medicaid rebate includes two key provisions: a most-favored-customer (MFC) clause governing prices for pharmaceutical products supplied to Medicaid recipients and a basic rebate of at least 15.1 percent of the wholesale price of brand-name drugs. The effect of the program on prices may be mixed. On one hand, economic theory suggests that most-favored-customer clauses commit firms to compete less aggressively in prices, implying that prices and firm profits should rise in the face of a MFC clause. In contrast, the basic rebate should lower prices and firm profits. Given the opposing effects on price, it is not clear a priori how the program will affect firm profits.

Several authors have modeled the effect of negotiated or regulated prices on firm behavior in the pharmaceutical industry by focusing on pricing strategies and profitability, each of which may affect the degree of innovation in the industry. Elzinga and Mills (1997) model the effect of intervention by hospitals and managed care organizations on prices to all consumers for prescription drugs. They show that prescription drug pricing influenced by managed care may result in lower prices for some consumers at the sole expense of pharmaceutical firms, where reduced drug prices lower drug company profits. While not discussed by the authors, this model would presumably result in lower levels of industry innovation due to a reduction in retained earnings. In contrast, Morton (1997) looks explicitly at the effect of Medicaid rebates on pharmaceutical prices for different classes of drugs. In tests of her theoretical model, she finds that the effects of the rebate program are small and relatively weak, with no effect for drugs with patent protection. Thus, her study implies that for newly patented drugs, the law had little immediate effect on firm profitability. In sum, price caps appear to reduce firm prices, which is consistent with strong industry opposition to price controls (PhRMA, 2000a). ${ }^{2}$

Given estimates of the price elasticity demand for pharmaceuticals, which range from approximately 0.1 to 0.3 in absolute value, decreases in the per unit price of pharmaceutical products will decrease firm revenue, which in turn may negatively influence earnings, $R \& D$, and drug innovation. ${ }^{3}$ Indeed, a study conducted by the department of Health and Human Services (1994) examined the relationship between spending controls and pharmaceutical research and development in Germany, Sweden, the United Kingdom, and France. In these countries, lower drug prices were found to weaken incentives for pharmaceutical research and development, where a 1 percent decrease in drug prices leads to 0.68 percent decrease in research and development spending. ${ }^{4}$

\subsection{FDA Regulation in the Drug Discovery Process}

Drug discovery is a complex, risky and time-consuming process, involving a great deal of regulation by the U.S. Food and Drug Administration (FDA), which imposes strict requirements on drug testing and development. On average drug companies spend $\$ 500$ million and 12-15 years of research and clinical trials to bring a new medicine to market (PhRMA, 2001a).

Innovation in the industry may be measured at several stages in the drug development process.

1. At the end of the basic research stage (also known as pre-clinical testing stage) a firm is required to file a Commercial Investigational New Drug (IND) Application with the FDA before beginning human testing of 
the new medicine. In the 1990s, this stage took approximately 3.8 years (DiMasi, 2001).

2. After completing three phases of clinical trials, if the drug is safe, a firm may submit a New Drug Application (NDA) to the FDA. This stage took an average of 8.6 years in the 1990s (DiMasi, 2001).

3. In the final stage, the FDA approval process results in New Chemical Entities (NCE), a subset of the larger class of New Drug Approvals (NDAs). NDAs include several types of new drugs and drug delivery systems: NCEs, New Indications, New Dosage Forms, New Dosing Regimens, and New Routes of Administration. In the 1990s this was by far the shortest and least expensive stage, lasting less than 1.8 years on average (DiMasi, 2001) and accounting for less than five percent of all research and development expenditures (PhRMA, 2001b).

Since 1938, pharmaceutical manufacturers have been required to provide scientific proof of product safety before putting drugs on the market. In 1962, Congress added two additional regulatory restrictions: a proof-ofefficacy requirement for new drug approval and additional requirements for testing Investigational New Drugs (Grabowski \& Vernon, 1983; Comanor, 1986). ${ }^{5}$ These new regulations resulted in a more costly and lengthy drug development process and intensified concerns about the impact of regulation on new drug discovery (Comanor, 1986).

Since 1962, there has been a decline in annual new drug introductions accompanied by strong upward trends in the cost, time, and risk associated with pharmaceutical R\&D (Hansen, 1979; DiMasi, Hansen, Grabowski, and Lasagna, 1991). The average time from clinical trials to FDA approval of drugs in the late 1960s and the 1970s was about six years, but by the 1980s this process took an average of nine years (DiMasi, Hansen, Grabowski, and Lasagna, 1991). In addition, time spent in the pre-clinical and clinical phases of development increased from 9.5 years in 1970s to 12.7 years from 1990-1996 (PhRMA, 2000b).

Since the 1984, three noteworthy legislative changes have reduced the burden of regulation and/or increased the payoff to research and development. First, in 1984, Congress passed the Drug Price Competition and Patent Term Restoration Act, permitting research-based companies to apply for up to five years of additional patent protection for new medicines. This change increased the benefits associated with bringing a new drug to market, compensating firms for time lost to the FDA review and approval process.

Second, a 1988 regulatory revision expanded patients' access to experimental therapies for serious diseases with no approved effective treatment, like HIV. This change shortened the drug review process and is likely to have increased the number of Commercial Investigational New Drug Applications.

Finally, in 1992, Congress passed the Prescription Drug User Fee Act (PDUFA), where pharmaceutical companies agreed to pay more than $\$ 325$ million in user fees to the FDA in exchange for a more timely review process. Between 1993 and 1997, these fees were used to hire 660 new reviewers (Wechsler, 2001), resulting in a 50 percent reduction in the approval time for New Chemical Entities (Tufts Center, 1999). This legislation is likely to have increased the number of New Drug Applications, New Drug Approvals, and New Chemical Entity Approvals.

\section{Data and Empirical Model}

As the literature review reveals, price regulation, in the form of rebates, is likely to negatively influence innovation in the pharmaceutical industry. To examine the effect of Medicaid rebates on various measures of industry innovation in the U.S., the relationship between pharmaceutical industry revenues and industry innovation will be estimated. After empirically establishing this relationship, the effect of Medicaid rebates on innovation will be examined.

Several measures of innovative outputs in the pharmaceutical industry will be considered: Commercial Investigational New Drug Applications, New Drug Applications, New Drug Approvals, and New Chemical Entities. As discussed above, these innovations reflect different stages of the R\&D process and/or indicate different types of innovations. Inputs into the production of the number of innovations include firm level spending on research and 
development, which in turn is influenced by sales and retained earnings. Data on drug applications and approvals were taken from annual reports and statistical reports of the Center for Drug Evaluation and Research and the FDA website. Annual domestic pharmaceutical industry sales and domestic R\&D expenditures were taken from the 2000 Pharmaceutical Industry Profile, published by the Pharmaceutical Research and Manufacturers of America (PhRMA). ${ }^{6}$

Graphs 1 and 2 show the number of innovations in each year, where data are available from 1970-2000 for New Drug Approvals, New Drug Applications, and New Chemical Entities, and data are available from 1983-2000 for Commercial Investigational New Drug Applications. Two key policy regime shifts are indicated on Graph 1, in 1984 and 1992. As discussed above, in 1984 the Drug Price Competition and Patent Term Restoration Act was passed, which allowed for additional patent protection, and in 1992 the Prescription Drug User Fee Act was passed, which allowed for shortened drug review time. Both acts may increase applications and approvals by increasing the amount of time drug companies have to recoup research and development costs. For Commercial INDs, a single regulatory shift is noted on Graph 2, where in 1988 regulation expanded patients' access to experimental therapies for serious diseases with no approved effective treatment. These three policy changes are incorporated into the empirical model, discussed below, using binary indicator measures equal to zero prior to the regulatory change and one otherwise.

Domestic U.S. sales in the industry and domestic R\&D spending are shown in Graph 3. Both have been increasing over time at an increasing rate. An empirical investigation of the relationship between sales and research and development reveals a very strong correlation between the two variables, where a one dollar increase in R\&D spending is associated with a $\$ 3.84$ increase in sales. Thus, sales alone are used in the subsequent analysis. ${ }^{7}$

\section{Graph 1: Annual Number of Pharmaceutical Innovations}

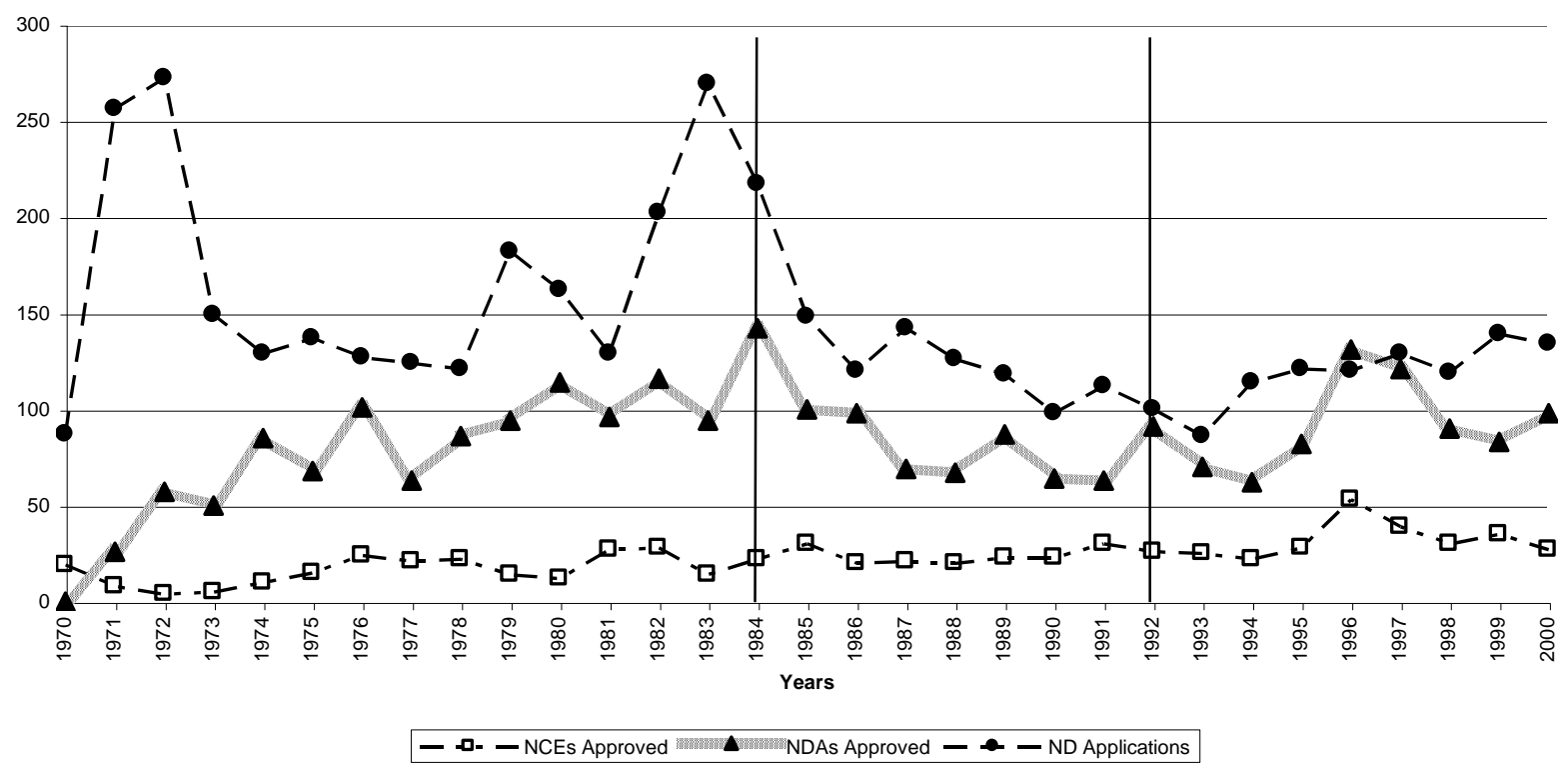


Graph 2: Annual Number of Commercial Investigational New Drugs (INDs)

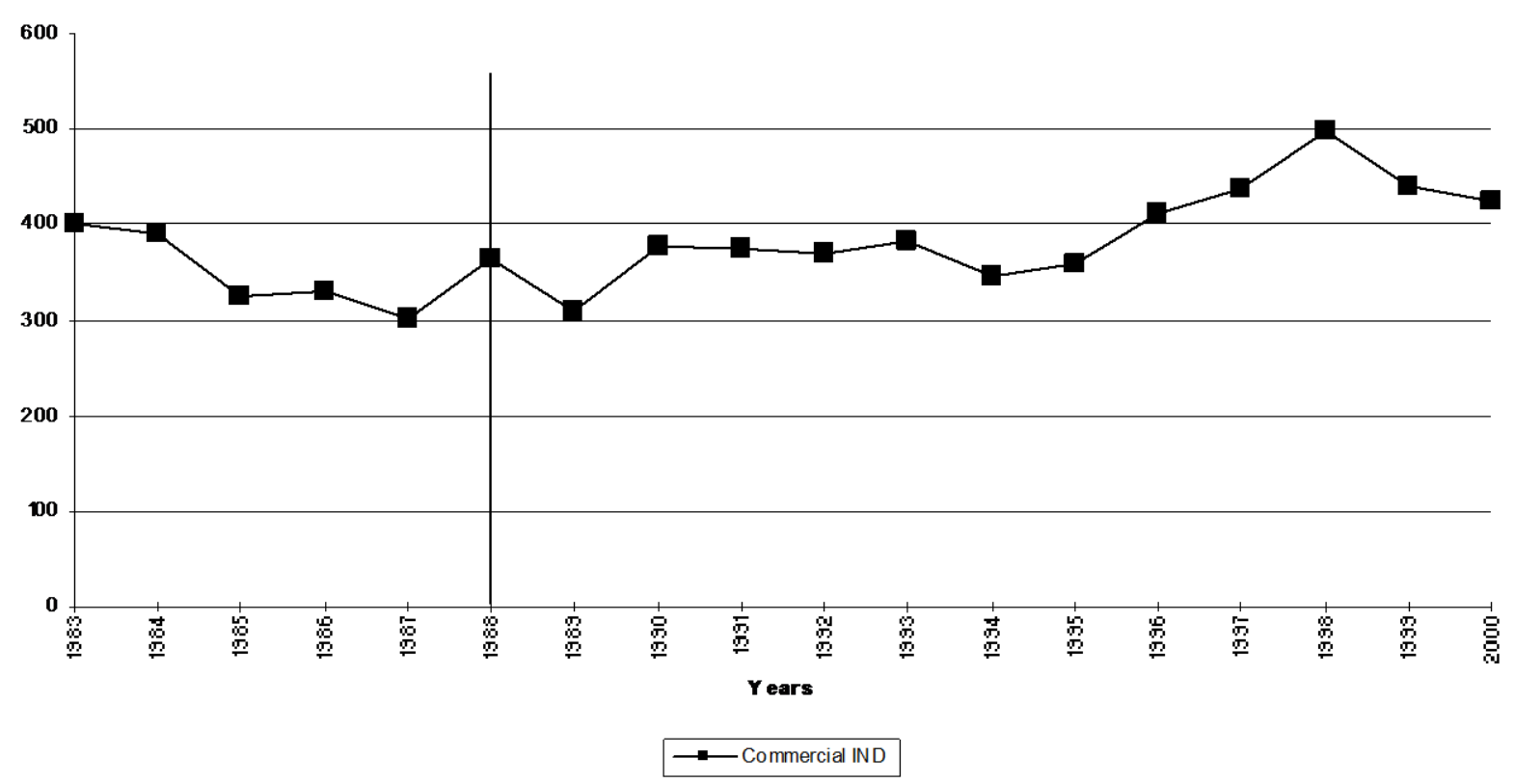

Graph 3: Annual Industry Sales and R \& D (U.S. in Millions \$)

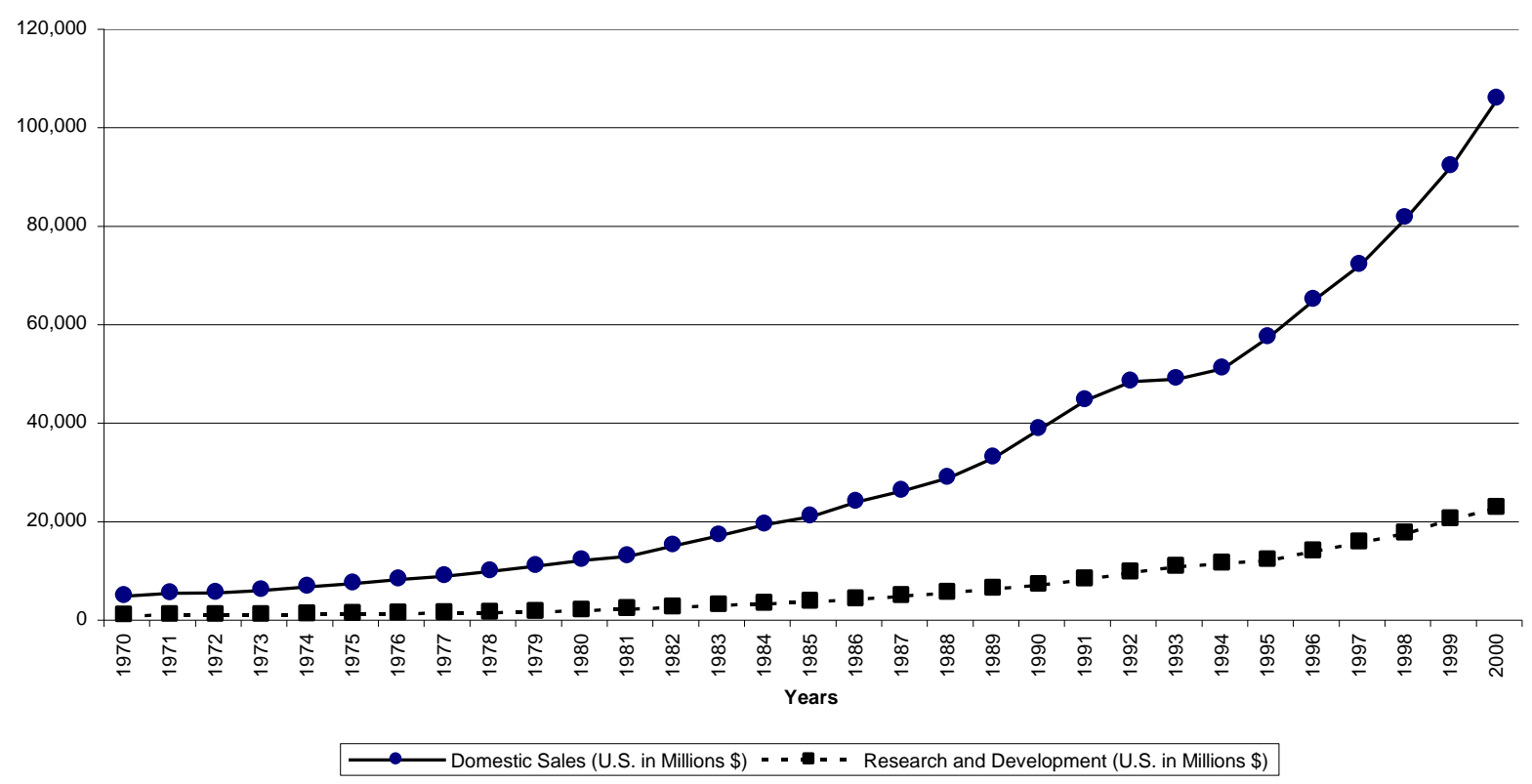


Innovation at time $t$ may depend on real sales over a number of periods:

$$
\text { Innovation }_{t}=\alpha+\sum_{i=1}^{n} \beta_{i} \text { PolicyChan geBinary }_{i}+\sum_{j=0}^{m} \delta_{t-j} \text { Sales }_{j}+\varepsilon
$$

where $n=2$ for ND Approvals, ND Applications, and NCEs and $n=1$ for Commercial INDs; and $m$ is the optimal number of current and lagged values of sales to be included in the specification.

Given that regression analysis can produce spurious results when variables contain stochastic trends (Granger and Newbold, 1974; Phillips, 1986), the data are examined for unit roots (i.e. stochastic trends) using standard Phillips-Perron (1988) tests. ${ }^{8}$ The results presented in Table 1 reveal that the hypothesis of a unit root cannot be rejected for New Chemical Entities Approved, Commercial Investigational New Drug Applications Filed, and Domestic U.S. Sales. ${ }^{9}$ Although the variables are governed by stochastic trends, if there exists a linear combination of them which is stationary and they are integrated of the same order, then they are cointegrated and share a common stochastic trend (Hamilton,1994). For example, use of the Engle and Granger (1987) procedure to test for cointegration reveals that pharmaceutical sales and research and development are cointegrated, an intuitive result. However, sales is not cointegrated with any of the innovation measures.

Table 1: Phillips-Perron Tests for Unit Roots

\begin{tabular}{lccccc} 
& $\begin{array}{c}\text { New Chemical } \\
\text { Entities } \\
\text { Approved }\end{array}$ & $\begin{array}{c}\text { New Drug } \\
\text { Applications } \\
\text { Approved }\end{array}$ & $\begin{array}{c}\text { New Drug } \\
\text { Applications } \\
\text { Filed }\end{array}$ & $\begin{array}{c}\text { Commercial } \\
\text { Investigational } \\
\text { New Drug } \\
\text { Applications } \\
\text { Filed }\end{array}$ & $\begin{array}{c}\text { Natural Log } \\
\text { Total Domestic } \\
\text { U.S. Sales }\end{array}$ \\
\hline \hline \multicolumn{1}{c}{ Test } & P-value & P-value & P-value & P-value & P-value \\
\hline PP no intercept & 0.3970 & 0.6360 & 0.3720 & 0.6640 & \\
PP intercept only & 0.1340 & $0.0060 * *$ & $0.0190 * *$ & 0.4560 & 0.9910 \\
PP intercept + trend & & & & & 0.9490 \\
PP differenced with intercept & $0.0010 * *$ & $0.0010 * *$ & $0.0010 * *$ & $0.0010 * *$ & $0.0070 * *$ \\
\hline \hline
\end{tabular}

Note: The null hypothesis is that the series is non-stationary. Two stars indicate significance at the one percent level, and one star indicates significance at the five percent level.

Since the hypothesis of a unit root cannot be rejected for New Chemical Entities Approved, Commercial Investigational New Drug Applications Filed, and Domestic U.S. Sales, the proper specification should involve regressing the first difference of each innovation on the first difference of sales. For ease of interpretation, the natural log of each variable is taken before taking the first difference, and the first difference of all innovation variables is taken. Thus, equation one is modified as follows:

$$
\Delta \text { Innovation }=\sum_{i=1}^{n} \beta_{i} \text { PolicyChan geBinary }_{i}+\sum_{j=0}^{m} \delta_{t-j} \Delta_{\text {Sales }_{t-j}}+\varepsilon
$$

where $n=2$ for ND Approvals, ND Applications, and NCEs and $n=1$ for Commercial INDs; $m$ is the optimal number of current and lagged values of sales to be included in the specification, where the optimal lag length for sales is determined by the Akaike Information Criteria (Akaike, 1973); $\Delta$ indicates the first difference; and all innovations and sales are in natural logs. 


\section{Empirical Results}

The empirical results are contained in Table 2. A small number of lags of sales is sufficient to characterize the relationship between each innovation and sales. The sum of estimated coefficients on sales growth and lagged sales growth is the elasticity, where the sum is uniformly positive. For example, for New Drug Applications Filed, the optimal specification includes current domestic sales growth and one lagged value of sales growth, where a one percent increase in the growth rate of sales implies a 2.65 percent increase in the growth rate of NDAs filed. Sales growth has the largest impact on growth in Commercial Investigational New Drug Applications and New Drug Applications Approved, but the coefficients are jointly significant only for the latter innovation measure. This may be due to the smaller sample for INDs. The changes in government regulation in 1984 and 1992 significantly affected New Drug Approvals in a positive manner, where the change in 1992 had a larger effect on increasing New Drug Approvals.

Table 2: Pharmaceutical Innovation Estimates

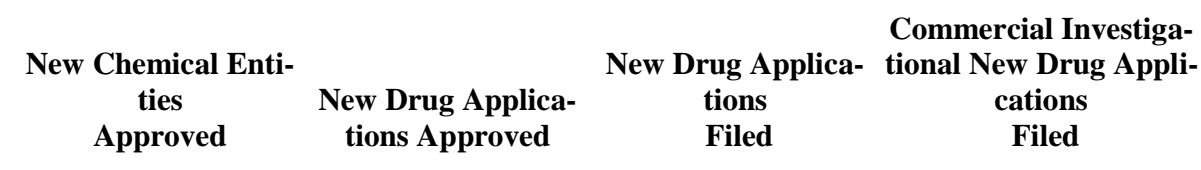

\begin{tabular}{|c|c|c|c|c|}
\hline Policy Change beginning 1984 & 0.4515 & $0.4113 *$ & -0.0217 & \\
\hline Policy Change beginning 1988 & & & & 0.0734 \\
\hline Policy Change beginning 1992 & -0.0945 & $0.4989 * *$ & -0.0406 & \\
\hline US Sales in Millions (\$) $t$ & 1.0741 & $2.8999 * *$ & 0.7092 & 0.5605 \\
\hline US Sales in Millions (\$) ${ }_{t-1}$ & & & $1.9409 * *$ & -0.0052 \\
\hline US Sales in Millions $(\$)_{t-2}$ & & & & $1.4342 * *$ \\
\hline US Sales in Millions $(\$)_{t-3}$ & & & & 0.9494 \\
\hline Sum of Coefficients on Sales & 1.0741 & $2.8999 * *$ & $2.6501 * *$ & 2.9389 \\
\hline Number of Observations & 30 & 29 & 29 & 17 \\
\hline $\mathbf{R}^{2}$ & 0.547 & 0.145 & 0.283 & 0.634 \\
\hline Akaike Information Criteria & -52.899 & -76.434 & -81.908 & -70.483 \\
\hline
\end{tabular}

Note: US Sales is the first difference of the natural log of US Sales. Each of the Innovation variables is the first difference of the natural log. Two stars indicates significance at the one percent level, and one star indicates significance at the five percent level, using two-tailed t-tests for the individual coefficients and F-tests for the joint significance of the coefficients on sales.

The results reveal that limiting sales growth through price regulation will have a negative effective on the growth of industry innovation. For example, if one assumed that the entire amount of the rebate would be added back to sales in the absence of the Medicaid rebate program, the average growth rate of sales in the 1992-2000 period would be increased from an average of 7.56 percent annually to 8.05 percent annually, as shown in Table 3 . That reduction in the growth rate of sales due to the Medicaid rebates translates into a reduction in the growth rate of innovation. 
Table 3: Predicted Pharmaceutical Innovation Estimates without Rebates

\begin{tabular}{lr} 
Average Annual Growth in Sales in Millions (1992-2000) & $7.5577 \%$ \\
Estimated Average Annual Growth in Sales in Millions with Rebates (1992-2000) & $8.0548 \%$ \\
\hline Estimated Effect of Rebate on Annual Growth Rate of: & $-0.5339 \%$ \\
$\quad$ New Chemical Entities Approved & $-1.4416 \%$ \\
New Drug Applications Approved & $-1.3174 \%$ \\
$\quad$ New Drug Applications Filed & $-1.4609 \%$ \\
Commercial Investigational New Drug Applications Filed & -0.26 \\
Estimated Effect of Rebate on Annual Number of Innovations: & -4.13 \\
$\quad$ New Chemical Entities Approved & -1.24 \\
$\quad$ New Drug Applications Approved & -4.17 \\
$\quad$ New Drug Applications Filed & \\
Commercial Investigational New Drug Applications Filed & \\
\hline \hline
\end{tabular}

Using values for average sales and innovations over the 1991-2000 period and the estimated coefficients in Table 2, one can predict the number of innovations lost due to the rebate program in an average year. For example, approximately four fewer new drug applications were approved each year, on average, than would have been approved if industry sales were increased by the amount of the rebate to Medicaid.

\section{Discussion}

Price controls for a Medicare Drug Benefit are strongly opposed by the pharmaceutical industry, where new price regulation associated with a Medicare drug benefit would increase the portion of the U.S. market covered by price controls from fourteen percent to over forty percent (PhRMA, 2000a). An examination of the relationship between sales growth and innovation growth in the industry demonstrates that increasing sales increases innovation in the industry. An understanding of the link between sales and innovation is crucial given the long drug discovery process and the limited life of patents.

The model provides a rough estimate of the opportunity cost of the Medicaid rebate program, where as many as four new drug approvals annually were lost due to the Medicaid rebate program. Some of the more conservative estimates of the effects of pharmaceutical innovation on health imply that a one-time R\&D expenditure of about $\$ 15$ billion (which is less than the amount of domestic pharmaceutical R\&D in 1997) subsequently saves 1.6 million life-years per year, whose annual value is about $\$ 27$ billion (Lichtenberg, 1998). Given that the social rate of return on pharmaceutical innovation appears to be quite high and the drug discovery process is quite long, additional price regulation in the industry may have a significant negative effect on current and future public health.

\section{Suggestions for Future Research}

The model presented above is suggestive of the macroeconomic effects of a specific type of price regulation in the pharmaceutical industry. However, the reduction in innovation is clearly occurring at the margin, and the reduction may be different for different classes of drugs. Future research should focus on the effect of price regulation on therapeutic groups or other classifications of pharmaceuticals to discover which drug classes are impacted most. In addition, the negative effects of price regulation may be offset to some degree by reductions in drug development time. More research needs to be done on the effect of reductions in drug development time on innovation in the industry. 


\section{End Notes}

1. It is hard to say that regulation-reducing innovation results in dynamic welfare losses, as there may be too much innovation in the competitive case. This paper endeavors to examine the potential effects of regulation on innovation, and the value of that innovation should be the subject of future research.

2. Genuardi, Stiller, and Trapnell (1996) and the Congressional Budget Office (1996) find some evidence that Medicaid rebates have coincided with a reduction in pharmaceutical discounts to some private third-party payers, even though average prices have fallen. While the rebates are likely to be welfare-reducing, an investigation into the distributional consequences of the rebate program are beyond the scope of this paper.

3. The elasticity estimates are from Folland, Goodman, and Stano (2001). Alexander, Flynn, and Linkins (1994) compute a price elasticity of demand for prescription drugs at a national level. For the U.S., they find that demand is relatively elastic (2.8), and the authors credit relatively little insurance coverage for prescription drugs during the period examined. However, the demand for prescription drugs for individuals covered by Medicaid is likely to be much more inelastic, given that Medicaid provides a generous drug benefit to beneficiaries with very low copayments and no deductibles (Cook, 1999).

4. In general, price regulation may not succeed in controlling drug spending, as was the case in four countries that implemented price regulation (GAO, 1994). Moreover, the GAO report argued that the effects of a price reduction in Canada and European countries may differ significantly from the effects of similar price reductions in the U.S., since these countries represent a relatively small share of global pharmaceutical market.

5. The law required firms to provide results of clinical tests on animals and research protocols for clinical trials to the FDA prior to testing in humans.

6. Only ethical pharmaceuticals are included in sales and R\&D measures. Domestic U.S. Sales are reported net of rebates and discounts, and they include sales by research-based companies within the United States. Domestic U.S. R\&D includes expenditures within the United States by research-based companies.

7. While the pharmaceutical industry is increasingly multinational in scope, historically, the U.S. has been the largest producer of drug development and innovation. Both U.S.-owned and foreign-owned research-based companies spent almost $\$ 22.5$ billion on R\&D within the United States in 2000, accounting for approximately thirty-six percent of global pharmaceutical R\&D (PhRMA, 2000b). Sales and Medicaid rebates have been converted to 1996 dollars using the GDP deflator for use in the subsequent analysis.

8. The unit root tests examine each time series to determine whether the time series being examined is stationary, i.e. whether the underlying stochastic process that generated the series can be assume to be invariant with respect to time.

9. Note that the goal of unit root tests is to find a parsimonious representation that gives a reasonable approximation to the true process, as opposed to determining whether or not the true process is literally $\mathrm{I}(1)$. (Hamilton, 1994). Augmented Dickey-Fuller tests were also conducted and yielded similar results.

\section{Bibliography}

1. "Prescription Drugs: Spending Controls in Four European Countries." Department of Health and Human Services, Washington, D. C., HEHS-94-30, 1994.

2. "Prescription Drugs: Prices and Regulation in Canada and Europe." General Accounting Office, Washington, D.C., GAO/T-HEHS-94-213, 1994.

3. "How the Medicaid Rebate on Prescription Drugs Affects Pricing in the Pharmaceutical Industry. "Congressional Budget Office, Washington, D.C., 1996

4. Center for Drug Evaluation and Research, U.S. Food and Drug Administration. "The CDER Handbook." http://www.fda.gov/cder/handbook/ (1987). 2001

5. “Impact Report: Clinical development time for new drugs drop $18 \%$, reversing 12 -year trend." Tufts Center for the Study of Drug Development, 1999.

6. Pharmaceutical Research and Manufacturers of America (PhRMA) (a). "Government in the Pharmaceutical Marketplace. Pharmaceutical Industry Profile 2000." http://www.phrma.org/publications/publications/profile00/chap6.phtml (2000). 2001

7. Pharmaceutical Research and Manufacturers of America (PhRMA) (b). "Regulatory and Legal Aspects of 
Drug Development. Pharmaceutical Industry Profile 2000."

http://www.phrma.org/publications/publications/profile00/chap3.phtml (2000). 2001

8. Center for Drug Evaluation and Research, U.S. Food and Drug Administration. "Approval Times (In Months) For NDAs and NMEs Approved Calendar Years 1986-2000."

http://www.fda.gov/cder/rdmt/CY00NDAAP.HTM (2001). 2001

9. Pharmaceutical Research and Manufacturers of America (PhRMA). (a) "Factsheet: Monthly Report from America's Pharmaceutical Companies." http://www.phrma.org/publications/documents/factsheets//200103-01.216.phtml (2001). 2001

10. Pharmaceutical Research and Manufacturers of America (PhRMA). (b). "Research and Development - The Key to Innovation. Pharmaceutical Industry Profile 2001" http://www.phrma.org/publications/publications/profile01/chapter2.pdf (2001). 2001

11. Akaike, H. "Information Theory and the Extension of the Maximum Likelihood Principle." Second International Symposium on Information Theory. Eds. V. N. Petrov and F. Csaki, Akailseoniai-Kiudo, Budapest, pp. $267-281,1973$.

12. Alexander, D. L., Flynn, J. E. and Linkins, L.A. "Estimates of the Demand for Ethical Pharmaceutical Drugs Across Countries and Time." Applied Economics, Vol. 26, No.8, pp. 821-826, 1994.

13. Comanor, W. S. "The Political Economy of the Pharmaceutical Industry." Journal of Economic Literature, Vol. 24, No. 3, pp. 1178-1217, 1986.

14. Cook, A. E. "Strategies for Containing Drug Costs: Implications for a Medicare Benefit." Health Care Financing Review, Vol. 20, No. 3, pp. 29-37, 1999.

15. DiMasi, J. A. "New Drug Development in the United States from 1963 to 1999." Clinical Pharmacology and Therapeutics Vol. 69, No. 5, pp. 286-296, 2001.

16. DiMasi, J. A., Hansen, R., Grabowski, H. and Lasagna, L. "The Cost of Innovation in the Pharmaceutical Industry." Journal of Health Economics, Vol. 10, No. 2, pp. 107-142, 1991.

17. Elzinga, K. G. and Mills, D. E. "The Distribution and Pricing of Prescription Drugs." International Journal of the Economics of Business Vol. 4, No. 3, pp. 287-299, 1997

18. Engle, R. F. and Granger, C. W. "Co-Integration and Error Correction: Representation, Estimation, and Testing." Econometrica Vol. 55, No. 2, pp. 251-276, 1987.

19. Folland, S., Goodman, A.C. and Stano, M. "The Economics of Health and Health Care." Prentice -Hall, Upper Saddle River, N.J., 2001.

20. Genuardi, J. S., Stiller, J. M. and Trapnell, G.R. "Changing Prescription Drug Sector: New Expenditure Methodologies.” Health Care Financing Review, Vol. 17, No. 3, pp. 191-204, 1996.

21. Grabowski, H. G. and Vernon, J. M. "The Regulation of the Pharmaceuticals: Balancing the Benefits and Risks.” American Enterprise Institute for Public Policy Research, Washington, D.C., 1983.

22. Granger, C. W. and Newbold, P. "Spurious Regressions in Econometrics." Journal of Econometrics, Vol. 2, No.2, pp. 111-120, 1974.

23. Hamilton, J. D. “Time Series Analysis.” Princeton University Press, Princeton, N.J.,1994.

24. Hansen, R. W. "The Pharmaceutical Development Process: Estimated of Current Development Costs and Times and the Effects of Regulatory Changes." Issues in Pharmaceutical Economics. ed. R. I. Chien. The Free Press, New York, NY, 1979.

25. Lichtenberg, F. R. "Pharmaceutical Innovation, Mortality Reduction, and Economic Growth." National Bureau of Economic Research: Working paper series. No. 6569, 1998.

26. Morton, F. S. "The Strategic Response of Pharmaceutical Firms to Medicaid Most-Favored-Customer Rules." RAND Journal of Economics, Vol.28, No.2, pp. 269-290, 1997.

27. Phillips, P. C. "Understanding Spurious Regressions in Econometrics." Journal of Econometrics, Vol. 33, No. 3, pp. 311-340, 1986.

28. Phillips, P. C. and P. Perron "Testing for a Unit Root in Time Series Regression.” Biometrika, Vol. 75, pp. 335-346, 1988.

29. Solow, R. M. "Technical Change and the Aggregate Production Function." The Review of_Economics and Statistics, Vol. 39, No. 3, pp.312-320, 1957.

30. Spitzer, P. G. "Regulating Pharmaceutical Profits Will Reduce Research" USA Today, August 23, 13A, 1999.

31. Wechsler, J. “ User Fees Under Fire.” Pharmaceutical Executive Vol. 24, No. 11, pp. 24-26. 2001. 